\section{Successful Treatment of Post-partum Renal Failure with Heparin}

British Medical fournal, 1970, 4, 221-222

Postpartum renal failure caused irreversible renal insufficiency in most if not all hitherto reported cases. There are no reports of successful treatment of this condition. Anticoagulant treatment for postpartum renal failure has been tried without success (Robson et al., 1968; McKay, 1969; Ogg and Cameron, 1969) or was of doubtful benefit (Clarkson et al., 1969), probably because it was instituted too late or used in inadequate dosage. We report here the beneficial effects of heparin given early in the course of this disorder.

\section{CASE RePORT}

A 29-year-old woman was admitted to this hospital on 28 December 1969 in the 35th week of her third pregnancy. Previously she had had two spontaneous deliveries after normal pregnancies. She complained of severe epigastric and back pain and was slightly dyspnoeic. The blood pressure was $200 / 110$, massive proteinuria was found, and the ankles were oedematous. There was no history of cardiac or kidney disease.

Treatment was initiated immediately, and about eight hours later she had an uneventful delivery of a 2,000-g. infant. The placenta was small and had areas of infarction typical of toxaemia. The blood loss was minimal and the uterus contracted well after the routine administration of Syntometrine. After delivery the blood pressure returned to normal. At no time was it under $100 / 80 \mathrm{~mm} . \mathrm{Hg}$. Catheterization of the bladder six hours after delivery produced $100 \mathrm{ml}$. of urine containing protein, erythrocytes, leucocytes, and granular casts. Urine was not secreted for the next eight days. After an additional two hours there was no response to $80 \mathrm{mg}$. of frusemide (Lasix) intravenously and a test dose of mannitol and an intravenous infusion of $1,000 \mathrm{ml}$. of glucose $10 \%$. At that time the blood urea was $45 \mathrm{mg} . / 100 \mathrm{ml}$., $\mathrm{Hb} 9.8 \mathrm{mg} . / 100 \mathrm{ml}$., and W.B.C. $11,000 / \mathrm{mm}^{3}{ }^{3}$ There was a shift to the left in the differential count. The reticulocyte count was $1.8 \%$; thrombocyte count $30,000 / \mathrm{mm}^{3}$ total serum bilirubin $2.0 \mathrm{mg} . / 100 \mathrm{ml}$; uric acid $13.1 \mathrm{mg}$. $/ 100 \mathrm{ml}$.; and creatinine $1.6 \mathrm{mg} . / 100 \mathrm{ml}$. Fibrinogen in the blood was $200 \mathrm{mg} . / 100 \mathrm{ml}$. (normal range $400-700 \mathrm{mg}$.). Disseminated intravascular clotting was tentatively diagnosed. This was confirmed later when the result of fibrinogen degeneration products measured in the plasma became available (Merskey et al., 1966). They showed a tenfold increase of the normal level.

Heparin therapy was started eight hours after delivery and a constant heparinaemia of 1,000-1,500 units/1. of plasma was maintained. The dose was given after heparin titration was done once or twice daily. Antibiotics were added to this treatment. Three haemodialyses were performed on the third, fifth, and ninth days of the anuria. Concomitant with this treatment the thrombocyte count and plasma fibrinogen level increased (see chart). Urinary flow was resumed on the eighth day postpartum. The urine output increased gradually and, after a brief polyuric phase stabilized at $2,000 \mathrm{ml}$.

The heparin therapy was maintained for 15 days after the onset of anuria. There was no bleeding from the uterus during this time. The reticulocyte count rose to $13.0 \%$ on the seventh day and gradually returned to normal. The total serum bilirubin rose to a peak of $6.7 \mathrm{mg} . / 100 \mathrm{ml}$. on the third ca\%, wit's a slight increase in the direct bilirubin. SGOT level was 256 units (normal below 40 units). There was a sustained rise in fibrinogen degeneration products which lasted until about the seventh week after delivery, when it returned to normal. Six months after the event a 24-hour endogenous creatinine test was $115 \mathrm{ml} . / \mathrm{min}$. and
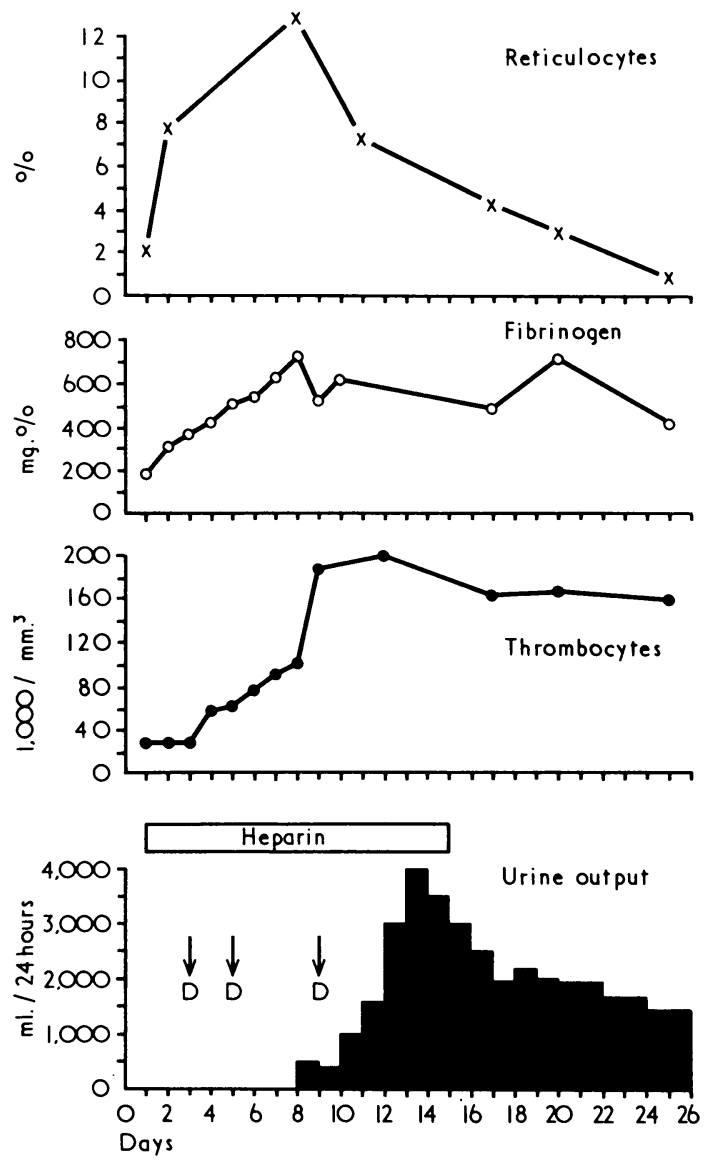

Blood values during treatment. D Dialysis.

maximal urinary concentrating ability was 816 mosmole $/ \mathrm{kg}$. $\mathrm{H}_{2} \mathrm{O}$ Minimal urinary $p \mathrm{H}$ was 4.9 . All these values are within normal limits in our laboratory. The infant developed normally following a 10-day stay in an incubator. The prolonged treatment with heparin precluded any consideration of kidney needle biopsy.

\section{Comment}

The tentative diagnosis of disseminated intravascular clotting was made in this patient because the acute renal failure was associated with hypofibrinogenaemia and thrombocytopenia and because of lack of evidence of overt fibrinolysis. The diagnosis was confirmed when an extreme increase in fibrinogen degeneration products was found at a later stage. Early heparin treatment stopped the disseminated intravascular clotting and most probably prevented irreversible renal damage from complete thrombosis of the renal microcirculation. Some degree of hepatic damage might also have occurred because of the jaundice and high SGOT level. 
Others have successfully treated similar patients with renal failure not connected with pregnancy (Hitzig, 1964; Piel and Phibbs, 1966; Habib et al., 1967; Kincaid-Smith et al., 1968; Sharpstone et al., 1968; Moncrieff and Glasgow, 1970). Nevertheless, in a recent extensive review of the literature McKay (1969) doubted the efficacy of heparin treatment in postpartum renal failure. In the reported cases of postpartum renal failure this treatment has been started relatively late in the course of the disease. This may explain the refractoriness of these cases to anticoagulant or heparin treatment.

Though it is difficult to draw conclusions from a single case the outcome in the present patient suggests that early and adequate heparin treatment should be considered in postpartum renal failure when disseminated intravascular clotting is suspected.

\section{TIMOR-TRITSCH, M.D. \\ O. S. BETTER, M.D. \\ I. TATARSKY, M.D. \\ C. Chaimowitz, M.D. \\ A. Peretz, M.D. \\ H. Abramovici, M.D.}

Departments of Obstetrics and Gynaecology, Nephrology, and Haematology, Rambam Government Hospital, Haifa.

\section{REFERENCES}

Clarkson, A. R., Meadows, R., and Lawrence, J. R. (1969). Australasian Annals of Mtdicine, 18, 209.

Habib, R., Mathieu, H., and Royer, P. (1967). Nephron, 4, 139.

Hitzig, W. H. (1964). Helvetica Paediatrica Acta, 19, 213.

Kincaid-Smith, P., Saker, B. M., and Fairlev, K. F. (1968). Lancet, 2, 1360.

McKay, D. G. (1969). California Medicine, 111, 186.

Merskey, C., Kleiner, G. J., and Johnson, A. J.(1966). Blood, 28, 1.

Moncrieff, M. W., and Glasgow, E. F. (1970). British Medical fournal, 3,

188.

Ogg, C. S., and Cameron, J. S. (1969). Lancet, 1, 1317.
Piel, C. F., and Phibbs, R. H. (1966). Pcdiatric Clinics of North America, 13, 295 .

Robson, J. S., Martin, A. M., Ruckley, V. A., and MacDonald, M. K. (1968). Quarterly fournal of Medicine, 37, 423.

Sharpstone, P., Evans, R. G., O'Shea, M., Alexander, L., and Lee, H. A. (1968). Archives of Disease in Childhood, 43, 711.

\section{Handlebar Injury}

British Medical fournal, 1970, 4, 222

One of the ambitions of young children is to ride a bicycle, and it is always the delight of small boys to enjoy its maximum potential. With the increasing amount of road traffic the cyclist is exposed to greater hazards, and the more modern cycles have been designed with a view not only to increasing the work efficiency but also to reduce the risk of road travel.

Injuries from falling off a bicycle can be multiple and severe, depending on the speed of travel and the mechanism of collision. Bicycle spoke injuries have been reported (British Medical fournal, 1969). They occur when the child puts his foot through the moving wheel, thus sustaining extensive lacerations.

Several advantages obtain from the small-wheel cycle. The centre of gravity is low, balance is thus easier to maintain, and the cycle is easier to control. There is much greater manœuvrability, especially in small spaces. This is particularly manifested in the steering column. There is no block to movement, and as a result the handlebars can be turned through over $360^{\circ}$. This is well illustrated in one of the cases described below. The boy's father demonstrated how on one occasion the brake cable had formed several turns round the steering column by the simple manœuvre of continuous rotation of the handlebars. In contrast the old-fashioned bicycle did not have such manœuvrability and there was a block to rotation of the steering column, either by the brake housing or by the crossbar. With the above advantages in the modern cycle loss of balance can result in a new type of injury. When the cycle is out of control rotation of the steering column continues, the handlebar grip is stopped only by impact, and the remainder of the rotation force is then expended at the site of impact. The resulting lesion is illustrated by the following four cases.

\section{Case Reports}

Case 1.-A boy aged 8 was admitted to hospital on 28 July 1969. He had fallen from his bicycle on 24 July. He stated that when turning right to avoid a hazard he lost balance and remembered falling on to the handlebars. On examination there was a large haematoma of the right groin, extending into the right iliac fossa. It later became infected and eventually required incision and drainage. He made a satisfactory recovery and was discharged on 7 August.

Case 2.-A boy aged 7 was admitted to hospital on 2 September 1969. He gave a history of a fall from his bicycle, when the handlebar ran into his right groin, causing a large haematoma. Shortly after admission grave circulatory disturbance of the right leg was evident and pulsation was absent. On exploration he was found to have a large tear at the saphenofemoral junction and extensive lacerations of the superficial femoral vein. It was not possible to reconstruct the superficial femoral vein, and ligation was required in order to secure haemostasis. He made a satisfactory recovery and was discharged on 17 September. Fortunately there has been only minimal oedema of the ankle.

Case 3.-A boy aged 7 was admitted to hospital on 8 September 1969. While riding his bicycle he fell against the handlebars and sustained an extensive laceration to the right side of the scrotum and the shaft of the penis. Surgical toilet and suture was undertaken. He made a satisfactory recovery and was discharged on 13 September.

Case 4.-A boy aged 9 was admitted to hospital on 19 September 1969. He gave a history of falling off his bicycle, the handlebar grip impinging in his left groin. There was a large haematoma of the left groin, which was treated conservatively. It gradually diminished in size and eventually resolved. He was discharged on 23 September.

\section{COMMENT}

The histories and clinical features of the above cases suggest that the injuries resulted from the impact of the handlebars in the groin. The cycles used were of the smallwheel type, though this can be definitely confirmed in only three cases, as the fourth accident occurred on a borrowed cycle, which was returned before it could be examined. Detailed inquiry into the accidents implied that in all cases the handlebars were rotated to avoid a hazard and the speed of travel combined with rotation of the steering column resulted in loss of control of the machine. During the fall the handlebar grip appeared to impinge in the groin. It is suggested that this is the mechanism of injury in the above cases, the point of impact being the groin.

Prevention of this type of injury requires a mechanical solution; either a mechanical block could be introduced to restrict rotation of the steering column or the handlebars themselves might be made collapsible on impact or be provided with telescopic grips.

The second consideration arising out of this study is the nature of the iniury. It depends almost entirely on the force at impact, and this can vary from simple abrasions to disruption and laceration of soft tissues.

The presence of a haematoma cannot be regarded lightlv, for if a major vessel is involved circulatory impairment of the limb may occur and require prompt treatment with perhaps vascular reconstruction. In Case 2 disruption of the femoral vein resulted in a rapidly enlarging haematoma and vascular impairment of the limb. Careful examination and often continual observation are therefore essential in these injuries.

\section{J. A. SEDDON, CH.M., F.R.C.S.} Consultant Surgeon, Warrington Infirmary and Dispensary, Warrington. 